\title{
Molecular Basis of Factor VIII Inhibition by Human Antibodies Antibodies That Bind to the Factor VIII Light Chain Prevent the Interaction of Factor VIII with Phospholipid
}

\author{
Morio Arai, Dorothea Scandella, and Leon W. Hoyer \\ Jerome H. Holland Laboratory for the Biomedical Sciences, American Red Cross Blood Services, Rockville, Maryland 20855
}

\begin{abstract}
Most antibodies to factor VIII have recently been shown to react with discrete regions of the factor VIII light chain (within the C2 domain) and/or the factor VIII heavy chain (within the amino-terminal segment of the A2 domain). The mechanism by which these antibodies, usually designated "factor VIII inhibitors," interfere with factor VIII function has been examined by determining their effect on factor VIII binding to a phospholipid. Factor VIII-phosphatidylserine binding was prevented by all seven factor VIII inhibitors that had strong factor VIII light chain reactivity and reduced by two inhibitors with weak anti-light chain reactivity. None of four inhibitors with heavy chain reactivity prevented factor VIII-phosphatidylserine interaction, though a partial reduction $(<50 \%)$ was noted for the intact IgG preparations. However, when Fab' fragments were substituted, no detectable reduction in factor VIII-phosphatidylserine binding was noted for the anti-heavy chain inhibitors and complete inhibition was retained by the anti-light chain inhibitors. These data suggest that a subset of factor VIII inhibitors, those that bind to light chain determinants, inactivate factor VIII by preventing its effective interaction with phospholipid.
\end{abstract}

\section{Introduction}

One of the most serious complications in the treatment of hemophilia A patients is the development of antibodies that inactivate factor VIII. These "factor VIII inhibitors" arise as alloantibodies in 5-20\% of patients with severe hemophilia A who have been treated with factor VIII concentrates (1). Factor VIII inhibitors also rarely occur as autoantibodies in normal individuals, in patients with autoimmune disorders, and in postpartum women (2).

Inhibitor antibodies are restricted in their light chain and heavy chain composition $(3,4)$, and they do not form immunoprecipitates or fix complement (3). Regions on the factor VIII protein with which many inhibitors react have recently been identified by immunoblotting experiments. Initial studies with thrombin cleavage fragments of factor VIII demonstrated that $>90 \%$ of inhibitors react with either or both the $44-\mathrm{kD}$

Address reprint requests to Dr. Hoyer, American Red Cross Laboratories, 15601 Crabbs Branch Way, Rockville, MD 20855.

Received for publication 10 August 1988 and in revised form 5 December 1988.

J. Clin. Invest.

(c) The American Society for Clinical Investigation, Inc. 0021-9738/89/06/1978/07 \$2.00

Volume 83, June 1989, 1978-1984 (heavy chain) and 72-kD (light chain) fragments (Fig. 1) (5). ${ }^{1}$ Subsequent more detailed epitope mapping by deletion analysis of recombinant factor VIII protein fragments has suggested that light chain-specific inhibitors recognize an epitope in the carboxy-terminal $17.3-\mathrm{kD}$, the $\mathrm{C} 2$ domain, and that heavy chain-specific inhibitors react with the amino-terminal 18.3$\mathrm{kD}$ segment of the $\mathrm{A} 2$ domain $(6,7)$ (Fig. 1).

In addition to information about the factor VIII epitopes that inhibitors recognize, it is important to know how these antibodies inactivate factor VIII. Among the possible functional effects are inhibition of thrombin cleavage which is necessary for factor VIII activation (8), blocking the interaction of factor VIII with either factor IXa or factor X, and interference with the binding of factor VIII to phospholipid.

We report here studies that examine the effect of factor VIII inhibitors on the interacton of factor VIII with phospholipid (9-12). As factor VIII light chain binds to phosphatidylserine (PS), ${ }^{2}$ but not to phosphatidylcholine or phosphatidylethanolamine (11), we examined the possibility that inhibitors that recognize light chain epitopes interfere with factor VIII binding to PS. This has been documented in data obtained for 13 heavy and light chain-specific inhibitors.

\section{Methods}

Materials. L- $\alpha$-Phosphatidyl-L-serine (PS) prepared from bovine brain was purchased from Sigma Chemical Co. (St. Louis, MO). Antihuman factor VIII monoclonal antibody MAB038 was obtained from Chemicon International, Inc. (El Segundo, CA) and anti-human factor VIII monoclonal antibody C8 (13) from JR Scientific (Woodland, CA). Peroxidase-labeled goat antibody to mouse immunoglobulins, 2.2'-azino-di-(3-ethyl-benzthiazoline sulfonate) (ABTS), and hydrogen peroxide were purchased from Kirkegaard \& Perry Laboratories, Inc. (Gaithersburg, MD). Purified human factor VIII (2,000 U of factor VIII procoagulant activity [VIII:C]/mg) was a gift from Hyland Therapeutics (Glendale, CA). A freshly dissolved solution had $16 \mathrm{U} / \mathrm{ml}$ VIII:C, $13 \mathrm{U} / \mathrm{ml}$ factor VIII antigen (VIII:Ag), and $0.32 \mathrm{U} / \mathrm{ml}$ von Willebrand factor antigen (vWF:Ag).

Factor VIII measurements. VIII:C was measured by a one-stage method using factor VIII-deficient plasma as substrate (14). VIII:Ag was measured by immunoradiometric assay using ${ }^{125} \mathrm{I}$-labeled $\mathrm{Fab}^{\prime}$ prepared from the plasma of a patient (CC) with an alloantibody to factor VIII (15). vWF:Ag was measured by immunoradiometric assay using a rabbit antibody (16). Citrate-anticoagulated plasma, pooled

1. The specific peptides produced by proteolytic processing of human factor VIII have been described by several investigators with slight variations in reported molecular masses. In this paper, the molecular masses of factor VIII peptides produced by thrombin are those reported by Fulcher et al. $(4,5)$.

2. Abbreviations used in this paper: ABTS, 2.2'-azino-di-(3-ethylbenzthiazoline sulfonate); PS, phosphatidylserine; vWF: Ag, von Willebrand factor antigen; VIII:Ag, factor VIII antigen; VIII: C, factor VIII procoagulant activity. 


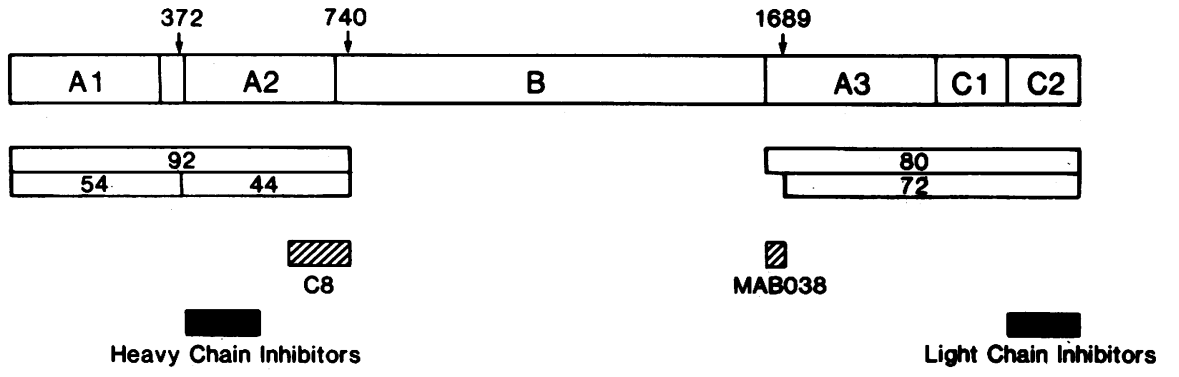

Figure 1. Schematic representation of factor VIII structure. The top bar shows the domain structure of factor VIII: the ceruloplasmin-like domains $(A 1, A 2, A 3)$, the carbohydrate-rich central domain $(B)$, and the duplication at the carboxy terminus $(C 1, C 2)(6)$. Arrows indicate the amino acid residues at thrombin cleavage sites. Thrombin cleavage products determined by SDS-PAGE are represented on the lower bar. The molecular mass estimates (in kilodaltons) are those reported by Fulcher et al. $(4,5)$. The solid boxes show those regions containing epitopes for human inhibitors, as determined by immunoblotting with the factor VIII protein deletion fragments (7). These studies have localized the binding to amino acid residues 379-538 (heavy chain inhibitors) and 2178-2332 (light chain inhibitors). The shaded boxes indicate the localization of monoclonal antibody binding sites: residues 606-740 for C8 (13) and 1649-1689 for MAB038.

from 10 normal donors, served as the standard ( $1 \mathrm{U} / \mathrm{ml})$ for VIII:C, VIII:Ag, and vWF:Ag measurements (16).

Characterization of antibodies to factor VIII. IgG was separated from factor VIII inhibitor plasmas by the caprilic acid method and Fab' was prepared by pepsin digestion (15). Inhibitors were characterized as type I or type II using criteria described by Gawryl and Hoyer (17). The inhibitor titer was determined by the Bethesda method (18). Dr. Carol Fulcher kindly determined the epitope specificities of the inhibitors by immunoblotting with human factor VIII and thrombin cleaved factor VIII, as previously described $(4,5)$. The factor VIII epitopes bound by the inhibitors and by the murine monoclonal antibody $\mathrm{C} 8$ were localized further by immunoblotting with the factor VIII protein deletion fragments described by Scandella et al. (7). These fragments were derived from a cDNA clone of factor VIII, and they were produced in Escherichia coli. The deletions removed contiguous segments of the 44- and 72-kD thrombin fragments. The epitope for MAB038 was determined by immunoblotting with human factor VIII and thrombin-cleaved factor VIII (19).

ELISA measurement of PS-bound factor VIII (PS-factor VIII). The ELISA, a modification of the method described by Bloom (11), used PS dissolved in methanol at $3 \mu \mathrm{g} / \mathrm{ml}$. The PS solution was added to microtiter plate wells $(100 \mu \mathrm{l} /$ well $)$ which were then air-dried at room temperature. To each well was added $200 \mu \mathrm{l}$ of $5 \mathrm{mg} / \mathrm{ml}$ gelatin in $0.05 \mathrm{M}$ Tris, $0.15 \mathrm{M} \mathrm{NaCl}$, pH 7.2 (blocking buffer) for $1 \mathrm{~h}$ at $37^{\circ} \mathrm{C}$. After the wells were washed with $0.02 \mathrm{M}$ phosphate buffer, $0.15 \mathrm{M}$ $\mathrm{NaCl}, 0.05 \%$ (vol/vol) Tween 20 (washing buffer), 100- $\mu$ l samples of factor VIII (diluted with blocking buffer) were added to each well. After $2 \mathrm{~h}$ of incubation at $37^{\circ} \mathrm{C}$, the wells were washed with washing buffer. Factor VIII binding to phospholipid was determined by adding $100 \mu \mathrm{l}$ of a monoclonal antibody to either the factor VIII heavy chain (C8) or the light chain (MAB038) (Fig. 1) (1 $\mu \mathrm{g}$ of $\mathrm{IgG} / \mathrm{ml}$ in blocking buffer). After a 2-h incubation at $37^{\circ} \mathrm{C}$, the wells were washed with washing buffer and peroxidase-conjugated anti-mouse immunoglobulin $(0.2$ $\mu \mathrm{g} / \mathrm{ml}$ in blocking buffer) was added to the wells. After a further 2-h incubation at $37^{\circ} \mathrm{C}$, the wells were washed and $100 \mu \mathrm{l}$ of ABTS solution containing $0.01 \%$ hydrogen peroxide was added. The absorbance at $405 \mathrm{~nm}$ was determined after a $15-$ min reaction at room temperature, and the factor VIII concentration was calculated from the average value for duplicate wells using a standard curve like that shown in Fig. 2. PS-factor VIII complex formation was blocked in a dosage-dependent manner by the addition of PS to the factor VIII in solution. Inhibition of $50 \%$ was noted at a PS concentration of $0.3 \mu \mathrm{g} / \mathrm{ml}$.

Comparison of factor VIII inhibitor effects on factor VIII:C activity and PS-factor VIII complex formation. Factor VIII in blocking buffer (1 U VIII:Ag/ml) was incubated for $2 \mathrm{~h}$ at $37^{\circ} \mathrm{C}$ with an equal volume of inhibitor IgG diluted in blocking buffer. Residual VIII:C was then determined for one part of the mixture and a separate $0.1-\mathrm{ml}$ aliquot was assessed by ELISA to determine if the factor VIII would bind to phospholipid. Factor VIII incubated with blocking buffer alone was the control for both VIII:C activity and PS-factor VIII complex formation assays. Each inhibitor was tested at least twice, once using serial half-log dilutions and once with serial twofold dilutions of inhibitor IgG. In every case, similar results were obtained in the two studies.

Control studies were carried out in which factor VIII was omitted from the mixture in order to be certain that the assay results were not due to anti-phospholipid antibodies. The 13-inhibitor IgG, tested at $100 \mu \mathrm{g} / \mathrm{ml}$, had no reactivity with PS in these assays, i.e., they had the same low (0.06-0.14) absorbance at $405 \mathrm{~nm}$ as did normal IgG.

Protective effect of PS on the immune inactivation of VIII:C activity. PS was homogenized and diluted to $30 \mu \mathrm{g} / \mathrm{ml}$ in barbital-buffered saline (15). $0.1 \mathrm{ml}$ of each PS solution was preincubated with $0.1 \mathrm{ml}$ of factor VIII ( $2 \mathrm{U} \mathrm{VIII:C/ml)} \mathrm{at} 37^{\circ} \mathrm{C}$ for $20 \mathrm{~min}$ before $0.1 \mathrm{ml}$ of inhibitor IgG was added. After $2 \mathrm{~h}$ of incubation at $37^{\circ} \mathrm{C}$, residual VIII:C was determined. In a separate set of mixtures, $0.1 \mathrm{ml}$ of inhibitor IgG was incubated with factor VIII ( $2 \mathrm{U}$ VIII:C/ml) at $37^{\circ} \mathrm{C}$ for $2 \mathrm{~h}$ before the $0.1 \mathrm{ml}$ of PS solution was added. After an additional 20-min incubation at $37^{\circ} \mathrm{C}$, residual VIII:C was measured.

\section{Results}

Properties of factor VIII inhibitor antibodies. We studied 13 human factor VIII inhibitor antibodies in detail. Their characteristics are summarized in Table I. When examined by immunoblotting analysis, five of the inhibitors bound to factor

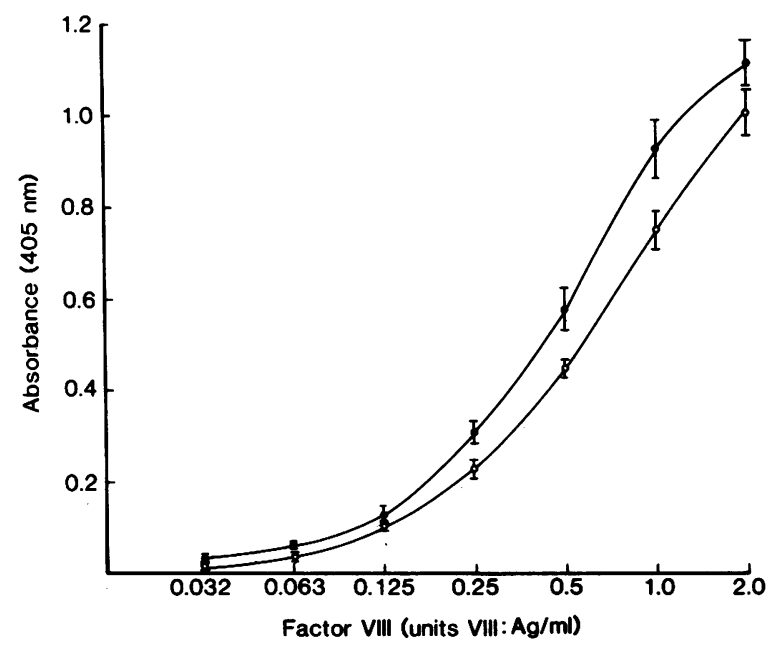

Figure 2. ELISA measurement of PS-factor VIII complex formation using two different monoclonal anti-factor VIII antibodies. Binding of increasing concentrations of factor VIII (units of VIII:Ag/ml) to PS-coated microtiter wells was measured using monoclonal antibody MAB038 (๑), reactive with a factor VIII light chain determinant, and C8 (o), a monoclonal antibody reactive with a factor VIII heavy chain determinant. The mean \pm SD are indicated $(n=8)$. 
Table I. Characterization of Human Anti-Factor VIII Inhibitors

\begin{tabular}{|c|c|c|c|c|}
\hline Inhibitor & Source & Type* & Titer & $\begin{array}{c}\text { Factor VIII } \\
\text { epitope specificity }\end{array}$ \\
\hline & \multicolumn{4}{|c|}{ Bethesda $U / m l$} \\
\hline MP & Hemophilic & I & 576 & Light chain \\
\hline $\mathbf{R I}$ & Hemophilic & I & 400 & Light chain \\
\hline $\mathbf{F}$ & Autoantibody & II & 400 & Light chain \\
\hline MR & Autoantibody & II & 960 & Light chain \\
\hline $\mathbf{L}$ & Autoantibody & II & 72 & Light chain \\
\hline $\mathbf{R M}$ & Hemophilic & I & 36 & Heavy chain \\
\hline $\mathbf{F M}$ & Autoantibody & I & 3,600 & Heavy chain \\
\hline JM & Autoantibody & I & 150 & Heavy chain \\
\hline $\mathbf{R C}$ & Autoantibody & II & 322 & Heavy chain \\
\hline NS & Autoantibody & I & 500 & $\begin{array}{l}\text { Light chain (weak) } \\
\text { plus heavy chain }\end{array}$ \\
\hline EM & Autoantibody & I & 50 & $\begin{array}{r}\text { Light chain (weak) } \\
\text { plus heavy chain }\end{array}$ \\
\hline $\mathrm{CC}$ & Hemophilic & I & 3,000 & $\begin{array}{l}\text { Light chain plus heavy } \\
\text { chain }\end{array}$ \\
\hline WC & Autoantibody & I & 3,600 & $\begin{array}{l}\text { Light chain plus heavy } \\
\text { chain }\end{array}$ \\
\hline
\end{tabular}

* Type I or II classification by reaction kinetics and degree of VIII:C inhibition (17)

VIII light chain epitopes, four reacted with the heavy chain, and four reacted with both chains $(4,5)$. Further epitope localization was obtained by immunoblotting with thrombin cleaved factor VIII and with deletion fragments of factor VIII (7). The epitope specificities determined by the two methods agreed in all cases. However, the weak reactions could not be detected with the factor VIII deletion fragments. The epitopecontaining regions are indicated in Fig. 1.

Both type I and type II inhibitors were tested, as were samples from both hemophilic (alloantibody) and autoantibody plasmas. The inhibitor titers ranged from 36 to 3,600 Bethesda units.

ELISA measurement of PS-factor VIII complex formation and effects of factor VIII inhibitors. Factor VIII binding to PS-coated microtiter plates was detected by monoclonal antibodies to human factor VIII designated C8 and MAB038 (Fig. 1). The amount of factor VIII bound, as measured by subsequent reactivity with anti-factor VIII (Fig. 2), was directly related to the amount of factor VIII added to the well. The effect of light chain inhibitors on the formation of PS-factor VIII complexes was initially measured with $\mathrm{C} 8$ and that of heavy chain inhibitors with MAB038 to avoid potential interference by the inhibitors on monoclonal antibody binding to the same chain. It was subsequently recognized that the two monoclonal antibodies gave similar data when used to detect factor VIII binding in the presence of the factor VIII inhibitors (Table II).

The effect of inhibitors on PS-factor VIII complex formation depended on the inhibitor specificity. Typical values for a heavy chain-specific and a light chain-specific inhibitor are given in Table II. As increasing amounts of IgG were added, residual VIII:C activity fell to $<3 \%$ in both cases. However, the light chain inhibitor (MP) reduced PS-factor VIII binding to $<6$ and $13 \%$ of that in control wells, while the heavy chain inhibitor (RM) IgG reduced binding by only 50 and $58 \%$. Both VIII:C inactivation and the reduction in PS-factor VIII complex formation by anti-light chain IgG were progressive over the 2-h incubation.
Table II. Effect of Factor VIII Inhibitor Antibodies on VIII:C Activity and on PS-Factor VIII Complex Formation

\begin{tabular}{|c|c|c|c|c|c|}
\hline \multirow[b]{2}{*}{ Inhibitor } & \multirow[b]{2}{*}{$\begin{array}{l}\text { Factor VIII } \\
\text { epitope } \\
\text { specificity }\end{array}$} & \multirow[b]{2}{*}{$\begin{array}{c}\text { Inhibitor } \\
\text { concentration }\end{array}$} & \multirow[b]{2}{*}{ Residual VIII:C } & \multicolumn{2}{|c|}{$\begin{array}{l}\text { PS-factor VIII } \\
\text { complex }\end{array}$} \\
\hline & & & & $\begin{array}{l}\text { Measured } \\
\text { with C8 }\end{array}$ & $\begin{array}{c}\text { Measured } \\
\text { with } \\
\text { MAB038 }\end{array}$ \\
\hline & & $m g / m l$ & & of control & \\
\hline \multirow[t]{8}{*}{ MP } & Light chain & 0.00 & 100 & 100 & 100 \\
\hline & & 0.02 & 74 & 98 & 86 \\
\hline & & 0.05 & 67 & 74 & 63 \\
\hline & & 0.07 & 65 & 61 & 55 \\
\hline & & 0.14 & 47 & 41 & 37 \\
\hline & & 0.29 & 11 & 14 & 14 \\
\hline & & 0.58 & $<3$ & 12 & $<6$ \\
\hline & & 1.15 & $<3$ & 13 & $<6$ \\
\hline \multirow[t]{8}{*}{$\mathbf{R M}$} & Heavy chain & 0.00 & 100 & 100 & 100 \\
\hline & & 0.54 & 89 & 100 & 96 \\
\hline & & 1.08 & 85 & 94 & 89 \\
\hline & & 1.80 & 80 & 85 & 88 \\
\hline & & 3.00 & 66 & 77 & 87 \\
\hline & & 4.50 & 47 & 70 & 84 \\
\hline & & 6.74 & 13 & 54 & 66 \\
\hline & & 10.78 & $<3$ & 50 & 58 \\
\hline
\end{tabular}

We tested 11 other inhibitors in the same way, and their effects on residual VIII:C activity and PS-factor VIII complex formation were determined (Fig. 3-5). IgG prepared from the four heavy chain-specific inhibitor plasmas inactivated all VIII:C activity but had only a moderate effect on PS-factor VIII complex formation ( $50 \%$ or less) (Fig. $3 \mathrm{~A}$ ). In contrast, the five light chain-specific inhibitors (Fig. $4 A$ ) inactivated VIII:C activity and PS-factor VIII complex formation to similarly low levels. Although two of the three type II anti-light chain inhibitors completely blocked PS-factor VIII complex formation, they did not completely inactivate VIII:C activity (17).

We also examined four inhibitors that bound to both heavy and light chain determinants. As shown in Fig. 5, two inhibitors, NS and EM, that reacted weakly with the light chain in immunoblotting experiments, had intermediate properties. IgG concentrations that completely inactivated factor VIII:C activity had an effect on PS-factor VIII complex formation between that of strictly light chain (Fig. 4) and heavy chain (Fig. 3) inhibitors. Inhibitors that reacted strongly with both heavy and light chain determinants (CC and WC) had properties like those of the light chain inhibitors. There was no $(<5 \%)$ inhibition of either VIII:C or PS-factor VIII complex formation by $0.1-10.0 \mathrm{mg} / \mathrm{ml}$ normal human IgG.

Although there was a consistent difference in the effect of light chain and heavy chain inhibitors on PS-factor VIII complex formation, the partial reduction by heavy chain-reactive IgG was unexpected. This was most likely due to a steric effect of the IgG-heavy chain interaction on PS-factor VIII complex formation in the test system. Fab' prepared from three heavy chain-reactive inhibitor IgGs had no ( $<5 \%)$ effect on PS-factor VIII complex formation even though VIII:C inactivating properties were intact (Fig. $3 \mathrm{~B}$ ), while the properties of one 
A

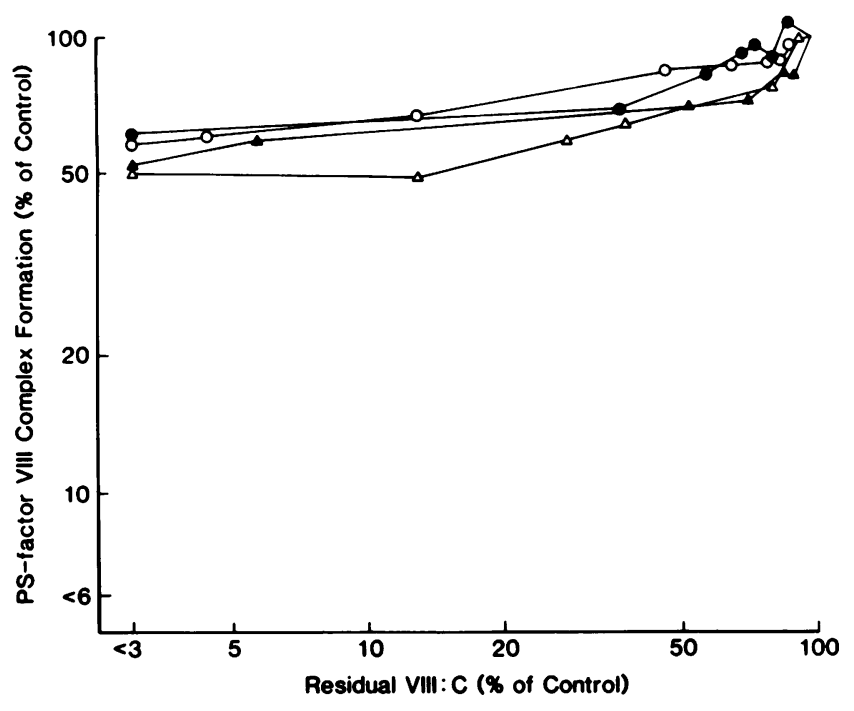

B

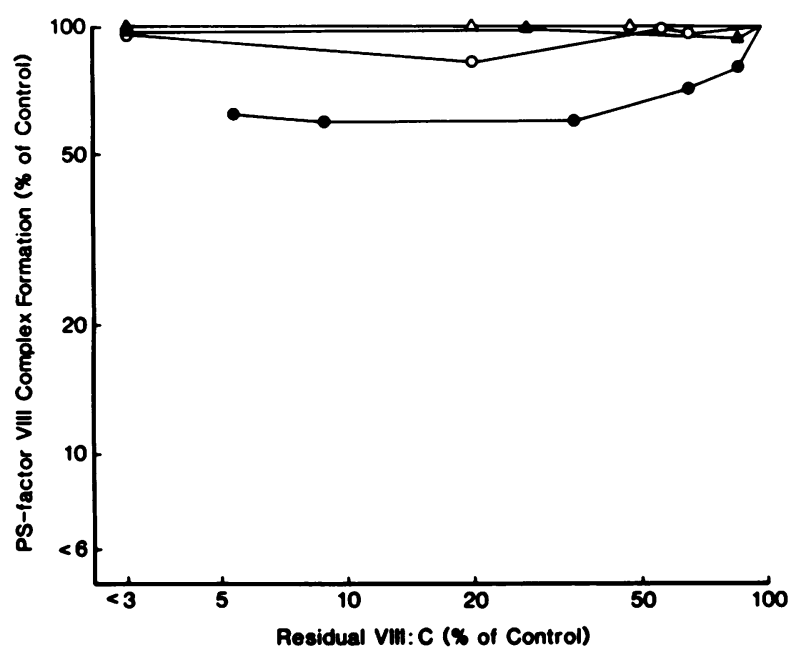

Figure 3. The effect of four anti-factor VIII inhibitors with heavy chain (44-kD) specificity on factor VIII:C activity and PS-factor VIII

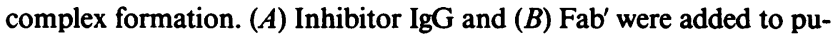
rified factor VIII (1 U VIII:C/ml) and the mixtures incubated for $2 \mathrm{~h}$. Residual VIII:C was then measured and PS-factor VIII complex formation was determined using the MAB038 monoclonal antibody. See Table II for representative data. Data points are noted for inhibi-

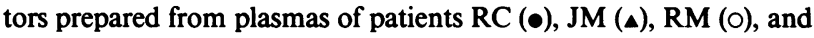
FM $(\Delta)$.

Fab' (RC) were similar to the IgG from which it was prepared. In contrast, three of four Fab' prepared from light chain specific inhibitor IgG had VIII:C inactivating and PS-factor VIII complex inhibiting effects like the IgG from which they were prepared (Fig. $4 B$ ) while one Fab' preparation (F) had only a modest effect on PS-factor VIII complex formation (40-60\% reduction) when tested in concentrations that inactivated 83-88\% of the VIII:C activity.

Protective effect of PS on VIII:C activity. Evidence of PSfactor VIII complex formation was also sought in experiments that determined the effect of PS on the VIII:C inactivation by the antibodies (20-23). Typical experiments are illustrated in Fig. 6. IgG prepared from the plasma of a patient with an inhibitor that had light chain specificity (MP) was incubated with factor VIII in two different dilution series. When PS was preincubated with factor VIII, VIII:C inhibition was reduced from that of a mixture of inhibitor plus factor VIII incubated together before the PS was added. An 85\% reduction in MP inhibitor activity (Bethesda units per microgram $\mathrm{IgG}$ ) was noted when PS was incubated with factor VIII before the antibody was added (Fig. $6 \mathrm{~A}$ ). In contrast, the two dilution series gave nearly identical inactivation results if the IgG had antiheavy chain specificity (Fig. 6 B).

Similar studies were carried out twice with each of the 13 inhibitors. Consistent results were obtained: a $74.5 \pm 7.5 \%$ re-

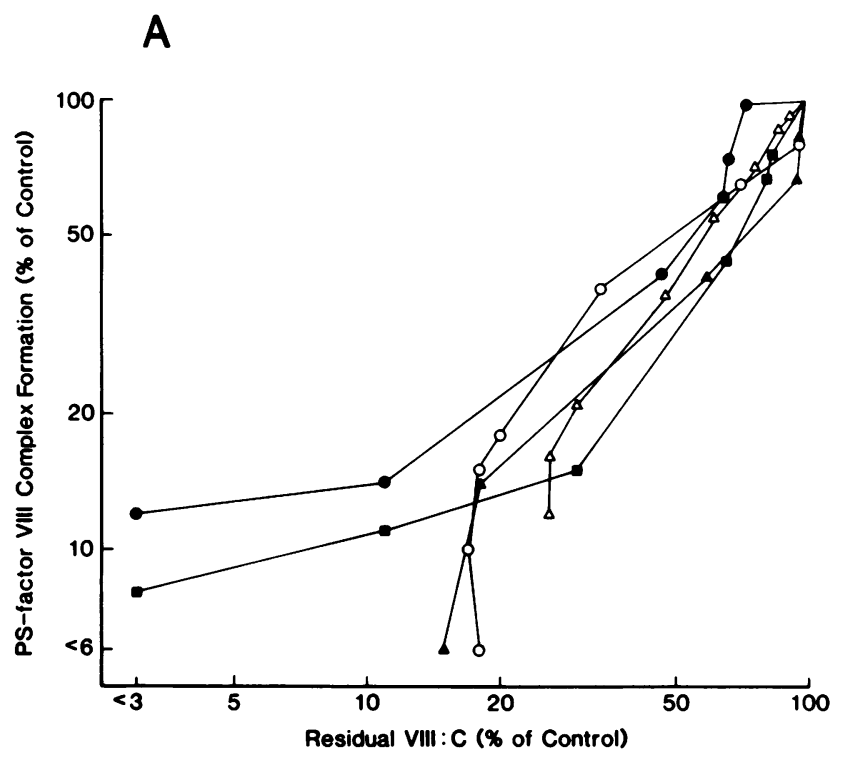

B

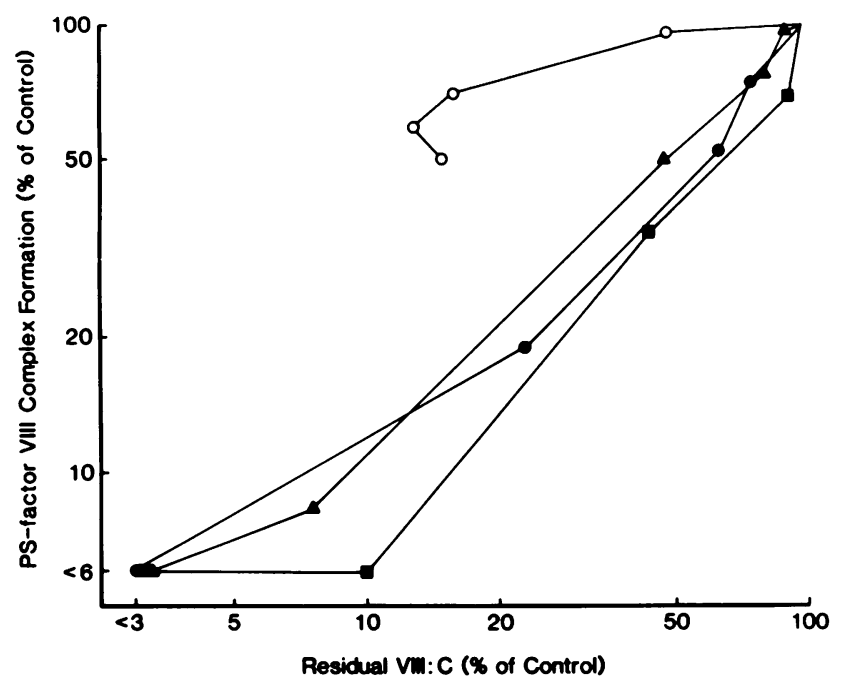

Figure 4. The properties of five anti-light chain (72-kD) inhibitors. Experimental details as noted for Fig. 3 except that PS-factor VIII complex formation was determined using a monoclonal antibody (C8) that binds to the factor VIII heavy chain. Data points are noted for $(A) \mathrm{IgG}$ and $(B) \mathrm{Fab}^{\prime}$ prepared from plasmas of inhibitor patients

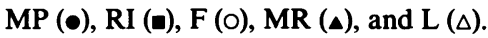




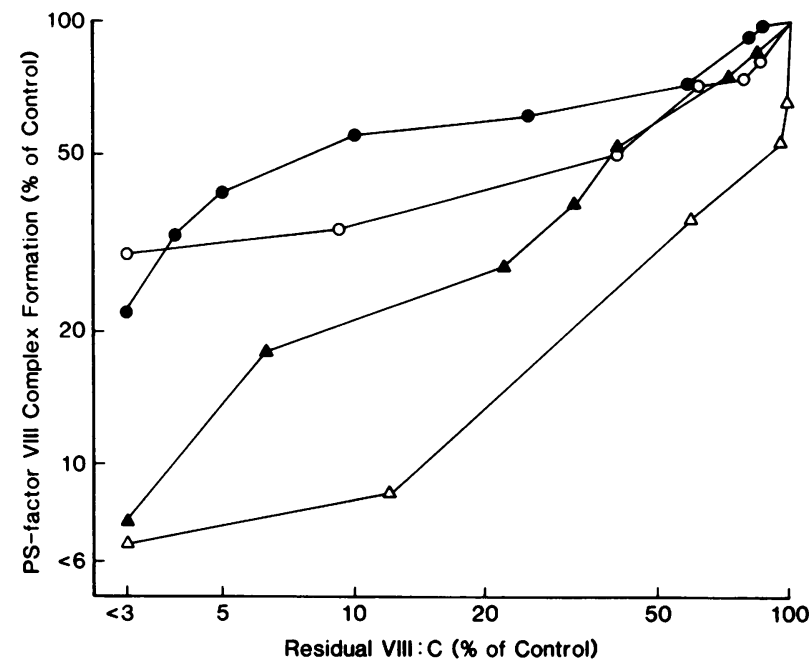

Figure 5. The properties of four anti-factor VIII inhibitor IgG preparations that react with both heavy chain and light chain determinants. Patients EM (๑) and NS (0) react strongly with the factor VIII heavy chain and weakly with its light chain. Patients CC ( $\Delta)$ and WC $(\Delta)$ react strongly with both the heavy and the light chains. Experimental details as described for Fig. 3. Fab' prepared from these four IgG had similar reactivity (data not shown).

duction in the inhibitor titer for the five antibodies that had light chain specificity when factor VIII was preincubated with PS, $16.5 \pm 12.1 \%$ for the four antibodies with heavy chain specificity, and $33.9 \pm 9.3 \%$ for the two antibodies that reacted strongly with both heavy chain and light chain determinants (CC and WC, Table I). These data indicate that factor VIII interacts with PS in a way that limits subsequent interaction with the factor VIII inhibitor.

\section{Discussion}

Our studies demonstrate a range of effects of factor FVIII inhibitors on the binding of factor VIII to immobilized PS. This interaction was strongly inhibited by all seven inhibitors that had light chain epitope specificity, but not by the four inhibitors that had only heavy chain specificity. Two inhibitors with weak reactivity for light chain epitopes, as well as strong heavy chain reactivity, had an intermediate effect.

Although anti-heavy chain factor VIII inhibitors did not affect PS-factor VIII complex formation to the extent that they inactivated factor VIII activity, a consistent partial $(<50 \%)$ effect on complex formation was noted. We interpret this as a steric effect of the IgG in this in vitro assay system. Fab' prepared from three inhibitor IgGs had no effect at all on the assay (Fig. $3 B$ ). This is good evidence that they react with a factor VIII epitope remote from the PS-binding site. A small $(<50 \%)$ effect of one of anti-heavy chain $\mathrm{Fab}^{\prime}(\mathrm{RC})$ suggests that there is heterogeneity within the small group of antiheavy chain inhibitors tested. Data for the anti-light chain inhibitors demonstrate that $\mathrm{Fab}^{\prime}$ can be as effective in blocking PS-factor VIII complex formation as the IgG from which it is prepared (Fig. $4 \mathrm{~B}$ ). The limited effect of one anti-light chain $F^{\prime} b^{\prime}(F)$ suggests that this inhibitor reacts with a light chain epitope that is close to the phospholipid-binding site, but that is separate from the epitope to which the other three Fab' bind (Fig. $4 \mathrm{~B}$ ). While interaction of inhibitor IgG factor VIII in vivo may have consequences very much like those detected on the surface of a microtiter well coated with PS, there may be subtle differences from those that occur on a more physiologic phospholipid surface. For this reason, it is not known if antiheavy chain inhibitors produce steric effects that inhibit factor VIII-phospholipid interactions in vivo.

The observations reported here are an interesting corollary to the studies reported by Barrowcliffe et al. (20), Yoshioka et al. (21), Broden et al. (22), and Kobayashi et al. (23) that phospholipid prevents the binding of some inhibitors to factor VIII. We have confirmed these results (Fig. $6 \mathrm{~A}$ ) and have demonstrated that the protective effect of phosphatidylserine is most marked for those inhibitors that bind factor VIII light chain determinants in immunoblotting studies $(4,5)$. The same subset of factor VIII inhibitors, those that bind to light chain determinants, completely block the factor VIII-phospholipid interaction (Figs. 4 and 5).

These data strongly suggest that inhibition of phospholipid binding is responsible for the in vivo and in vitro anti-factor VIII properties of antibodies that react with factor VIII light chain determinants. This conclusion is consistent with studies reported by Bloom for recombinant factor VIII fragments. The carboxy-terminal $80-\mathrm{kD}$ (light chain) polypeptide was observed to bind to PS, like the intact molecule, while there was no detectable binding of the purified amino-terminal region
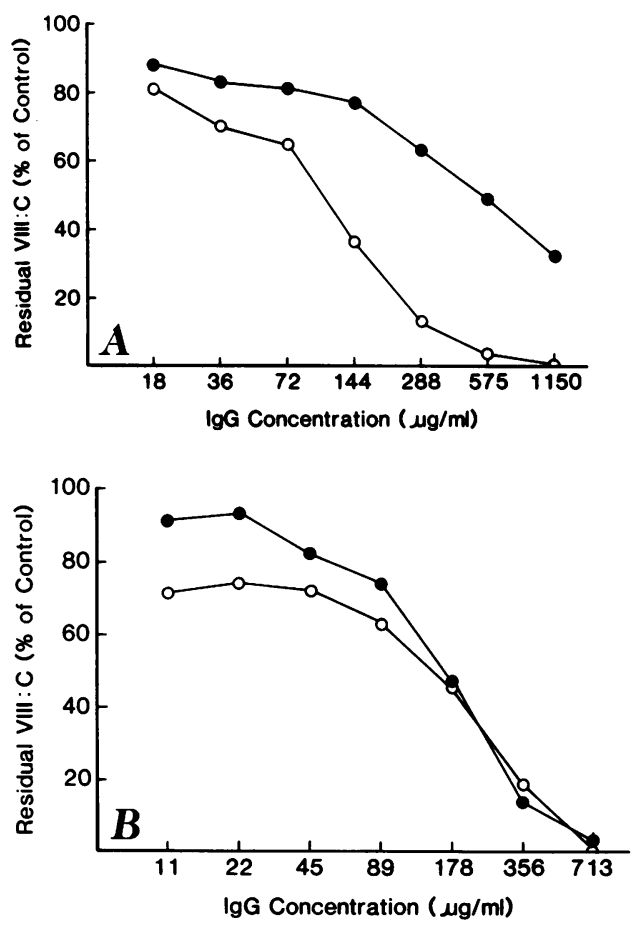

Figure 6. Effect of PS on factor VIII inactivation. $(A)$ A light chain specific inhibitor IgG (MP) and $(B)$ a heavy chain specific IgG (RC) were used in these experiments. Factor VIII $(2 \mathrm{U}$ VIII:C/ml) was preincubated with phosphatidylserine $(30 \mu \mathrm{g} / \mathrm{ml})$ for $20 \mathrm{~min}$, inhibitor IgG added, and the mixture incubated for $2 \mathrm{~h}$ before VIII:C assay (•). Also shown is a mixture in which factor VIII (2 U VIII:C/ml) was incubated with inhibitor IgG for $2 \mathrm{~h}$ before the addition of PS $(30 \mu \mathrm{g} / \mathrm{ml})$. Residual VIII:C was then measured after an additional 20-min incubation (O). Standard curves for VIII:C measurement were prepared using factor VIII incubated with buffer in place of inhibitor. 
90/115-kD (heavy chain) polypeptides to PS (11). Using immunologic methods, Kemball-Cook and colleagues have also obtained data suggesting that the factor VIII phospholipidbinding site is on the $80-\mathrm{kD}$ light chain (12).

The epitopes recognized by the light chain inhibitors have been previously localized within the factor VIII C2 domain (7). Since PS-factor VIII interaction is prevented by these inhibitors, it is likely that the phospholipid-binding site is located within the $\mathrm{C} 2$ domain of human factor VIII. However, in light of the generally consistent structural and functional homologies between the factor V and factor VIII (24), further studies are needed to reconcile our observations with recent data for the interaction of bovine factor $\mathrm{V}$ with phospholipid vesicles $(25,26)$. While it is clear that the carboxy-terminal (light chain) 74-kD polypeptide of activated bovine factor $\mathrm{V}$ binds to phospholipid vesicles (25), the major phospholipid-binding site appears to be within the A3 domain (26). These studies do not exclude the possibility of lipid binding by the $\mathrm{C} 2$ region as well, however, and the $\mathrm{C}$ domains of factor VIII and factor V have a $20 \%$ amino acid homology with the discoidins $(6,24)$, lectins from Dictyostelium discoideum that have binding affinity to negatively charged lipids like PS (27).

Confirmatory data for the hypothesis that anti-light chain inhibitors interfere with hemostasis by preventing factor VIIIphospholipid interactions may come in the future from studies of dysfunctional factor VIII. Although a mutant form of factor VIII with defective phospholipid-binding properties has not been identified, our data suggest that mutations or a small deletion in the $\mathrm{C} 2$ domain could generate that kind of molecule. Few hemophilic plasmas have enough dysfunctional factor VIII protein to examine phospholipid-binding properties, however, and the analysis of factor VIII molecular pathology is at a very early stage (28).

The studies reported here, as well as the recent report by Foster et al. (29) identifying a discrete binding region for an anti-factor VIII inhibitory alloantibody (threonine ${ }^{351}$-serin $^{372}$ ), begin to clarify the mechanisms by which factor VIII inhibitors interfere with factor VIII procoagulant activity. These techniques may be helpful in localizing the ways in which other factor VIII inhibitors act. Identification of the inhibitor binding regions and their mechanism of action should also lead to a better understanding of factor VIII structure-function relationships. This information may in turn suggest new ways to approach the treatment of patients with factor VIII inhibitors (30).

\section{Acknowledgments}

We thank Mora Mattingly and Norma Trabold for technical assistance, Debbie Wilder for manuscript preparation, and Hyland Therapeutics Division of Baxter Healthcare for providing highly purified factor VIII.

This work was supported in part by U.S. Public Health Service grants HL-36099 and RR-05737.

\section{References}

1. Gill, F. M. 1984. The natural history of factor VIII inhibitors in patients with hemophilia A. In Factor VIII Inhibitors. L. W. Hoyer, editor. Alan R. Liss, Inc., New York. 19-29.

2. Shapiro, S. S., and M. Hultin. 1975. Acquired inhibitors to the blood coagulation factors. Semin. Thromb. Hemostasis. 1:336-385.
3. Hoyer, L. W., M. S. Gawryl, and B. de la Fuente. 1984. Immunochemical characterization of factor VIII Inhibitors. In Factor VIII Inhibitors. L. W. Hoyer, editor. Alan R. Liss, Inc., New York. 73-85.

4. Fulcher, C. A., S. De Graff Mahoney, and T. S. Zimmerman. 1987. FVIII inhibitor IgG subclass and FVIII polypeptide specificity determined by immunoblotting. Blood. 69:1475-1480.

5. Fulcher, C. A., S. De Graff Mahoney, J. R. Roberts, C. K. Kasper, and T. S. Zimmerman. 1985. Localization of human factor FVIII inhibitor epitopes to two polypeptide fragments. Proc. Natl. Acad. Sci. USA. 82:7728-7732.

6. Vehar, G. A., B. Keyt, D. Eaton, H. Rodriguez, D. P. O'Brien, F. Rotblat, H. Oppermann, R. Keck, W. I. Wood, R. N. Harkins, E. G. D. Tuddenham, R. M. Lawn, and D. J. Capon. 1984. Structure of human factor VIII. Nature (Lond.). 312:337-342.

7. Scandella, D., S. De Graaf Mahoney, M. Mattingly, D. Roeder, L. Timmons, and C. A. Fulcher. 1988. Epitope mapping of human factor VIII inhibitor antibodies by deletion analysis of factor VIII fragments expressed in Escherichia coli. Proc. Natl. Acad. Sci. USA. 85:6152-6156.

8. Pittman, D. D., and R. J. Kaufman. 1988. Proteolytic requirements for thrombin activation of anti-hemophilic factor (factor VIII). Proc. Natl. Acad. Sci. USA. 85:2429-2433.

9. Lajmanovich, A., G. Hudry-Clergeon, J. M. Freyssinet, and G. Marguerie. 1981. Human factor VIII procoagulant activity and phospholipid interaction. Biochim Biophys. Acta. 678:132-136.

10. Andersson, L. O., and J. E. Brown. 1981. Interaction of factor VIII-von Willebrand factor with phospholipid vesicles. Biochem. $J$. 200:161-167.

11. Bloom, J. W. 1987. The interaction of rDNA factor VIII, factor VIII $_{\text {des-797-1562 }}$ and factor VIII $_{\text {des-797-1562-derived peptides with phospho- }}$ lipid. Thromb. Res. 48:439-448.

12. Kemball-Cook, G., S. J. Edwards, K. Sewerin, L. O. Andersson, and T. W. Barrowcliffe. 1987. The phospholipid-binding site of factor VIII is located on the $80 \mathrm{kD}$ light chain. Thromb. Haemostasis. 58:222. (Abstr.)

13. Rotblat, F., D. P. O'Brien, F. J. O'Brien, A. H. Goodall, and E. G. D. Tuddenham. 1985. Purification of human factor VIII:C and its characterization by Western Blotting using monoclonal antibodies. Biochemistry. 24:4294-4300.

14. Breckenridge, R. T., and O. D. Ratnoff. 1962. Studies on the nature of the circulating anticoagulant directed against antihemophilic factor: with notes on an assay for antihemophilic factor. Blood. 20:137-149.

15. Lazarchick, J., and L. W. Hoyer. 1978. Immunoradiometric measurement of the factor VIII procoagulant antigen. J. Clin. Invest. 62:1048-1052.

16. Hoyer, L. W. 1972. Immunologic studies of antihemophilic factor (AHF, factor VIII). IV. Radioimmunoassay of AHF antigen. $J$. Lab. Clin. Med. 80:822-833.

17. Gawryl, M. S., and L. W. Hoyer. 1982. Inactivation of factor VIII coagulant activity by two different types of human antibody. Blood. 60:1103-1109.

18. Kasper, C. K., L. M. Aledort, R. B. Counts, J. R. Edson, J. Fratantoni, D. Green, J. W. Hampton, M. W. Hilgartner, J. Lazerson, P. H. Levine, C. W. McMillan, J. G. Pool, and S. S. Shapiro. 1975. A more uniform measurement of factor VIII inhibitors. Thromb. Diath. Haemorrh. 34:869-872.

19. Fulcher, C. A., J. R. Roberts, L. Z. Holland, and T. S. Zimmerman. 1985. Human factor VIII procoagulant protein. J. Clin. Invest. 76:117-124.

20. Barrowcliffe, T. W., G. Kemball-Cook, and E. Gray. 1983. Binding to phospholipid protects factor VIII from inactivation by human antibodies. J. Lab. Clin. Med. 101:34-43.

21. Yoshioka, A., I. R. Peake, B. L. Furlong, R. A. Furlong, J. C. Giddings, and A. L. Bloom. 1983. The interaction between factor VIII clotting antigen (VIIICAg) and phospholipid. Br. J. Haematol. 55:2736.

22. Broden, K., J. E. Brown, C. Carton, and L. O. Andersson. 1983. 
Effect of phospholipid on factor VIII coagulant activity and coagulant antigen. Thromb. Res. 30:651-660.

23. Kobayashi, I., S. Lamme, and I. M. Nilsson. 1984. The interaction between factor VIII clotting antigen and phospholipids in genetic variants of hemophilia and von Willebrand's disease. Thromb. Res. 35:66-75.

24. Kane, W. H., and E. W. Davie. 1986. Cloning of a cDNA coding for human factor $\mathrm{V}$, a blood coagulation factor homologous to factor VIII and ceruloplasmin. Proc. Natl. Acad. Sci. USA. 83:68006804.

25. Higgins, D. L., and K. G. Mann. 1983. The interaction of bovine factor $\mathrm{V}$ and factor $\mathrm{V}$-derived peptides with phospholipid vesicles. J. Biol. Chem. 258:6503-6508.

26. Krishnaswamy, S., and K. G., Mann. 1988. The binding of factor Va to phospholipid vesicles. J. Biol. Chem. 263:5714-5723.
27. Bartles, J. R., N. J. Galvin, and W. A. Frazier. 1982. Discoidin I-membrane interactions. II. Discoidin I binds to and agglutinates negatively charged phospholipid vesicles. Biochim. Biophys. Acta. 687:129-136.

28. Antonarakis, S. E., H. Youssoufian, and H. H. Kazazian. 1987. Molecular genetics of hemophilia A in man (factor VIII deficiency). Mol. Biol. Med. 4:81-94.

29. Foster, P. A., C. A. Fulcher, R. A. Houghten, S. de Graaf Mahoney, and T. S. Zimmerman. 1988. Localization of the binding regions of a murine monoclonal anti-factor VIII antibody and a human anti-factor VIII alloantibody, both of which inhibit factor VIII procoagulant activity, to amino acid residues threonine ${ }^{351}$-serine s. $^{365}$ of the factor VIII heavy chain. J. Clin. Invest. 82:123-128.

30. Kemball-Cook, G., and T. W. Barrowcliffe. 1986. Factor VIII concentrates contain factor VIII procoagulant antigen bound to phospholipid. Br. J. Haematol. 63:425-434. 